\title{
Subsoiling Impact on Soil Physical Structure, Root Activity, Photosynthetic Characteristics, and Water Use Efficiency in Maize
}

\author{
Weiping Yan ${ }^{1}$, Lihua Zhang ${ }^{1}$, Chen $\mathrm{Xu}^{1}$, Hongxiang Zhao ${ }^{1}$, Guobo Tan ${ }^{1}$, Ning Sun ${ }^{1}$, Fei $\mathrm{Li}^{1}$, Yan $\mathrm{Gu}^{2 *}$ and Shaofeng \\ Bian $^{1 *}$ \\ ${ }^{1}$ Jilin Academy of Agricultural Sciences, Crop water efficient scientific observation experiment stations at Gongzhuling, Jilin \\ Changchun 130033, China \\ ${ }^{2}$ Jilin Agricultural University, Jilin Changchun 130118, China
}

*For correspondence: guyan810831@163.com; bsf8257888@sina.com; yanweiping0@126.com

Received 16 October 2020; Accepted 04 January 20201; Published 25 March 2021

\begin{abstract}
In order to promote the comprehensive production capacity and yield of farmland soil, the effects of subsoil tillage on soil structure, root activity, photosynthetic characteristics, dry matter accumulation, yield and water use through long-term positioning research in semi-arid areas were studied. This study was started in 2011 and investigated in the 2015-2016 research cycle. The experiment was conducted with five treatments including $30 \mathrm{~cm}$ subsoiling (SS-30) and $40 \mathrm{~cm}$ subsoiling (SS-40) before spring sowing, $30 \mathrm{~cm}$ (AS-30) and $40 \mathrm{~cm}$ (SS-40) between rows after autumn harvest and no subsoiling (CK). The effects of subsoiling on soil properties, crop growth, yield and water use of maize in semi-arid areas were investigated. The results showed that subsoiling significantly reduced the penetration resistance and bulk density of soil, and significantly increased the soil moisture content from subsoiling to the surface. Subsoiling increased $G_{S}$ and $C_{i}, T_{r}, P_{n}$ and WUE in maize plants, and significantly increased root activity. Subsoiling significantly increased dry weight of aboveground part and root, significantly decreased root shoot ratio, and significantly increased WUE per plant. Subsoiling significantly increased 100 grain weight, yield and WUE of population. Subsoiling can effectively improve the soil structure, enhance the water storage capacity of the soil in arid areas, delay water loss, improve root activity, net photosynthetic rate, dry matter accumulation and WUE, and promote crop growth and yield of maize. Subsoiling in autumn has the best effect on soil improvement. Increasing the subsoiling depth properly can improve their effects, which will gradually less with the passage of time. (C) 2021 Friends Science Publishers
\end{abstract}

Keywords: Subsoiling; Soil penetration resistance; Roots activity; Photosynthetic characteristics; Water use efficiency; Yield

\section{Introduction}

The shortage of water resources is an important factor limiting the sustainable development of agriculture in arid and semi-arid areas, and it promotes the degradation of cultivated land, which is the main reason for the imbalance of soil ecological balance and the decline of productivity (Wei et al. 2019). As an important conservation tillage measure, subsoiling has good ecological and economic effects (Li et al. 2011; He et al. 2018). The outline of northeast black soil protection plan (2017-2030) issued in June 2017 pointed out that deep subsoiling and deep ploughing should be promoted in dry farming areas of Northeast Plain to enhance the sustainability of farmland system in black soil area to consolidate and enhance the comprehensive agricultural production capacity.

Traditional shallow rotary tillage makes the topsoil shallower, the bottom of the plow thickens, and the soil's ability to conserve water and soil moisture decreases, and soil erosion is serious. As a result, the farmland ecological environment continues to deteriorate, seriously affecting agricultural production and crop yield (Wang et al. 2000; Ghosh et al. 2005; Zhao et al. 2014). Studies have shown that deep pine can effectively break the bottom of the plough, reduce surface runoff, increase precipitation infiltration, promote the circulation of soil gas, improve drought-resistant and moisture retention ability of soil (Han et al. 2009; Ingrid et al. 2012; Wang et al. 2019). Deep pine can improve soil structure, increase soil porosity, promote root growth and binding, and improve root uptake of soil water and nutrients (Baumhardt et al. 2008; Qi et al. 2012; Ping et al. 2020). Deep pine can also promote the growth of crops, increase the accumulation of dry matter, and improve grain yield and water use efficiency of crops (He et al. 2006; Xie et al. 2020).

Previous research on subsoiling has made more 
progress. Zhang et al. (2020) studied soil physical and chemical properties of spring maize under subsoiling rotation tillage, showing that it could improve soil structural stability and fertility. Wang et al. (2019) reported that that the effect of subsoiling in summer on soil bulk density was better than in autumn, and the soil nutrient content of subsoiling in autumn was higher than in summer. Liu et al. (2020) studied the period and mode of subsoiling, which showed that lateral subsoiling was more conducive to summer maize root system absorbing soil nutrients. Kaur and Arora (2019) studied the nitrogen absorption and yield under subsoiling, which indicated that it was helpful to solve the limitation of drought on nitrogen absorption and maize yield. Schneider et al. (2017) studied the crop yield under subsoiling, and showed that the effects of subsoiling on crop yield in different regions were different due to the differences of soil types and climate. Therefore, subsoiling is an effective measure to improve soil productivity.

In view of the lack of water resources, soil plough bottom thickening and plough layer structure degradation caused by long-term mechanized operation. The effects of subsoiling on soil structure, crop growth, material accumulation and water use was studied.

\section{Materials and Methods}

\section{Survey of experimental field}

The experiment was conducted in Taonan comprehensive experimental base $\left(45^{\circ} 20^{\prime} \mathrm{N}, 122^{\circ} 49^{\prime} \mathrm{E}, 156.8 \mathrm{~m}\right.$ a.s.l) of Jilin Academy of Agricultural Sciences from 2011 to 2016. The base is located in the western edge of Songnen Plain, with continental monsoon climate in North Temperate Zone. It is dry in spring with little wind and rain, hot and concentrated rainfall in summer, moderate cold and warm in autumn, severe cold and little snow in winter. The annual average sunshine duration is $3005.3 \mathrm{~h}$, the average annual solar radiation is $532.2 \mathrm{~J} / \mathrm{cm}^{2}$, the average annual evaporation is $2083.3 \mathrm{~mm}$, the active accumulated temperature $\geq 10^{\circ} \mathrm{C}$ is $2910^{\circ} \mathrm{C}$, and the annual frost-free period is 142 days. The soil type is light chernozem. The specific nutrient composition of soil is shown in Table 1.

During the maize planting period, seasonal drought occurred in May, July and September of 2015 and May, August and September of 2016 (Fig. 1). The annual precipitation was $476.8 \mathrm{~mm}$ in 2015, including $394 \mathrm{~mm}$ from May to September, and $371.6 \mathrm{~mm}$ in 2016, including $325.7 \mathrm{~mm}$ from May to September (Fig. 1). The maize was irrigated three times with $30 \mathrm{~mm}$ irrigation each time in 2015 and 2016

\section{Experimental design}

Since 2011, subsoiling has been carried out once every two years. In this study, the data of the cycle from 2015 to 2016 are used research. Mechanical subsoiling was carried out before sowing in spring and after harvesting in autumn in
2015.

Five treatments were set up: $30 \mathrm{~cm}$ subsoiling before sowing in spring (SS-30), $40 \mathrm{~cm}$ subsoiling (SS-40) before sowing in spring, $30 \mathrm{~cm}$ between rows after autumn harvest (AS-30), $40 \mathrm{~cm}$ between rows after autumn harvest (AS40), and no subsoiling (CK). Xianyu 335 was selected as the test maize variety. The sowing density was 60000 plants / $\mathrm{hm}^{2}$. The fertilization rate was $213 \mathrm{~kg} / \mathrm{hm}^{2}$ of pure nitrogen, $75 \mathrm{~kg} / \mathrm{hm}^{2}$ of $\mathrm{P}_{2} \mathrm{O}_{5}$ and $75 \mathrm{~kg} / \mathrm{hm}^{2}$ of $\mathrm{K}_{2} \mathrm{O} .35 \%$ nitrogen fertilizer and all phosphorus and potassium fertilizer were applied before sowing, and the remaining $65 \%$ nitrogen fertilizer was applied at jointing stage.

\section{Determination of soil properties}

The total nitrogen, phosphorus, potassium, hydrolyzeable nitrogen, available phosphorus and potassium, organic matter and $\mathrm{pH}$ value of $0-60 \mathrm{~cm}$ soil layer were measured before sowing in 2015. The total nitrogen content was determined by $\mathrm{H}_{2} \mathrm{SO}_{4}$ digestion Kjeldahl nitrogen determination method, the total phosphorus content was determined by concentrated $\mathrm{H}_{2} \mathrm{SO}_{4}-\mathrm{HClO}_{4}$ digestion molybdenum antimony resistance colorimetry method, and the total potassium content was determined by $\mathrm{NaOH}$ melting flame photometer method. Determination of hydrolyzed nitrogen content by Alkali Solution Diffusion, determination of available phosphorus content by molybdenum antimony colorimetric method, ammonium acetate extraction flame photometric method was used to determine the content of available potassium, determination of soil organic matter by potassium dichromate oxidation-external heat method (Bao 2000). Soil $\mathrm{pH}$ was measured by METTLER TOLEDO 320 using the soil water ratio was 1:2.5.

The bulk density of $0-40 \mathrm{~cm}$ soil layer was measured by ring knife method, and soil compactness was measured by JC-JSD-01 soil compactness tester after harvesting in autumn of 2015 and 2016. The moisture content of $0-100$ $\mathrm{cm}$ soil was measured by drying method at different growth stages of maize in 2016.

TTC reduction amount and root activity were determined by TTC reduction method (Zou 1997). The absorption area of the root was measured by colorimetry according to the change of the concentration of the test solution. It is known that the area of $1 \mathrm{mg}$ methylene blue as a single molecular layer is $1.1 \mathrm{~m}^{2}$. Based on this, the total and active absorption area of root system can be calculated. The calculation formula is as follows:

Root activity $(\mathrm{g} / \mathrm{g} / \mathrm{h})=\mathrm{TTC}$ reduction $(\mathrm{g}) /$ root weight $(\mathrm{g})$ $\times$ time $(\mathrm{h})$

Total absorption area $\left(\mathrm{m}^{2}\right)=\left[\left(\mathrm{C} 1-\mathrm{C}^{\prime}{ }^{\prime}\right) \times \mathrm{V} 1\right]+[(\mathrm{C} 2-$

$$
\left.\left.\mathrm{C} 2^{\prime}\right) \times \mathrm{V} 2\right] \times 1.1
$$

Active absorption area $\left(\mathrm{m}^{2}\right)=\left[\left(\mathrm{C} 3-\mathrm{C}^{\prime}{ }^{\prime}\right) \times \mathrm{V} 3\right] \times 1.1$

The ratio surface $=$ the absorption area of the root $/$ the volume of the root 
Subsoiling Effect on Soil Structure, Root Activity, Photosynthesis and WUE of Maize / Intl J Agric Biol, Vol 25, No 4, 2021

Table 1: The soil nutrient composition in the experimental field

\begin{tabular}{llllllll}
\hline $\begin{array}{l}\text { Measure the depth } \\
(\mathrm{cm})\end{array}$ & $\begin{array}{l}\text { Total N } \\
(\mathrm{g} / \mathrm{kg})\end{array}$ & $\begin{array}{l}\text { Total P } \\
(\mathrm{g} / \mathrm{kg})\end{array}$ & $\begin{array}{l}\text { Total K } \\
(\mathrm{g} / \mathrm{kg})\end{array}$ & $\begin{array}{l}\text { Hydrolytic N } \\
(\mathrm{mg} / \mathrm{kg})\end{array}$ & $\begin{array}{l}\text { Available P } \\
(\mathrm{mg} / \mathrm{kg})\end{array}$ & $\begin{array}{l}\text { Available K } \\
(\mathrm{mg} / \mathrm{kg})\end{array}$ & $\begin{array}{l}\text { Organic matter } \\
(\mathrm{g} / \mathrm{kg})\end{array}$ \\
\hline $0-20$ & 1.039 & 0.506 & 24.335 & 64.456 & 18.035 & 83.829 & 24.335 \\
$20-40$ & 0.977 & 0.420 & 23.787 & 58.606 & 15.225 & 69.637 & 23.787 \\
$40-60$ & 0.886 & 0.253 & 22.380 & 43.709 & 5.071 & 46.399 & 23.430 \\
\hline
\end{tabular}

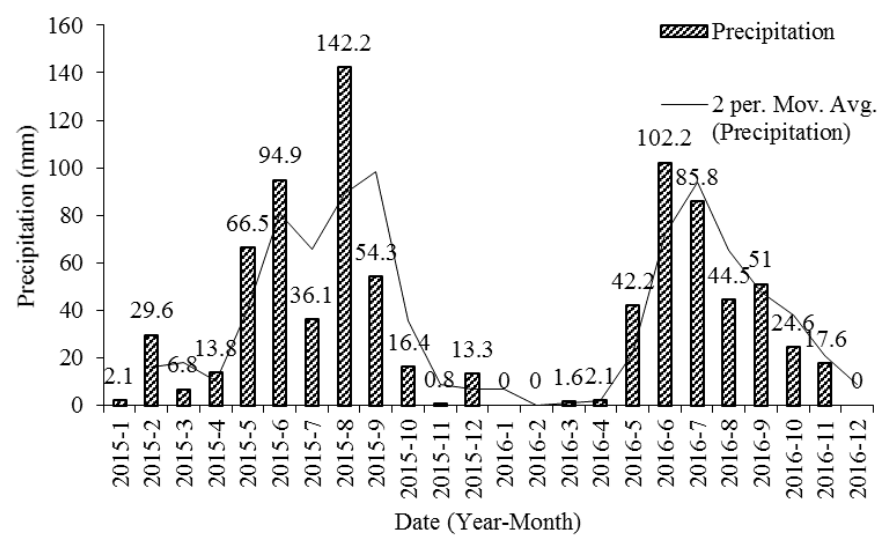

Fig. 1: Precipitation in the experiment area in 2015 and 2016

The "C" is the original concentration of solution $\mathrm{mg} / \mathrm{mL}$, "C ' " concentration after extraction $\mathrm{mg} / \mathrm{mL}$, "V" root volume $\mathrm{ml}$, "1, 2, 3" beaker number.

The stomatal conductance $\left(G_{s}\right)$, intercellular $\mathrm{CO}_{2}$ concentration $\left(C_{i}\right)$, transpiration rate $\left(T_{r}\right)$ and net photosynthetic rate $\left(P_{n}\right)$ of ear leaves were measured by LC Pro+ automatic portable photosynthesis instrument at silking stage, at 9 a.m. to 11 a.m., and the light intensity was set at $1700 \mu \mathrm{mol} / \mathrm{m}^{2} / \mathrm{s}$ (Zhu et al. 2011). The leaf water use efficiency (WUE) was calculated according to the formula: leaf WUE $=P_{n} / T_{r}$.

Determination of total aboveground dry weight and root dry weight in $0-40 \mathrm{~cm}$ soil. The fresh samples were put into the drying oven, sterilized at $105^{\circ} \mathrm{C}$ for $30 \mathrm{~min}$, dried at $80^{\circ} \mathrm{C}$ to constant dry weight, and the root-shoot ratio was determined. The water balance method was used to calculate the farmland water consumption (ET) and WUE per plant. According to the formula: $\mathrm{ET}=$ precipitation in growth period + irrigation water + (soil water before sowing - soil water at harvest) (Zhai et al. 2016), WUE per plant = above-ground biological yield/ET.

All ears within $20 \mathrm{~m}^{2}$ were collected and weighed at the harvest time of maize. According to the average single ear weight, 20 even ears were selected and air-dried, and the number of grains per ear and the weight of 100 grains were measured, then the yield (14\% water content in grain) and population WUE were calculated, according to the formula: population WUE $=$ Yield/ET .

\section{Statistical analysis}

Analysis of variance was conducted to determine the effect of subsoiling on soil and maize. Differences between means were distinguished through the least significant difference (LSD) test at 0.05 confidence level. The experimental data were processed and analyzed by Excel 2013 and DPS 15.10 software.

\section{Results}

\section{Effects of subsoiling on soil properties}

Soil penetration resistance, also known as soil compactness, is an indicator of soil strength. In 2015, the compactness of subsoiling treatment in $0-30 \mathrm{~cm}$ soil layer was significantly lower than CK. In 0-10 cm soil layer the compactness of AS-40 was significantly lower than of AS-30, SS-40 and SS-30. In 10-20 cm soil layer the compactness of AS-30 and AS-40 was significantly lower than SS-30 and SS-40. In 20-30 cm soil layer, the compactness of SS-40 and AS-40 was significantly lower than of AS-30 and SS-30. The compactness of AS-40 and SS-40 in 30-40 cm soil layer was significantly lower than in AS-30, SS-30 and CK, and the compactness of AS-40 was significantly lower than SS40 (Fig. 2A).

In 2016, the compactness of subsoiling treatment in 0 $30 \mathrm{~cm}$ soil layer was significantly lower than CK. In 0-10 $\mathrm{cm}$ and $10-20 \mathrm{~cm}$ soil layer the compactness of AS-30 was significantly lower than SS-40, SS-30 and AS-40. In 20-30 $\mathrm{cm}$ soil layer the compactness of SS-40 and AS-40 was significantly lower than of AS-30 and SS-30. The compactness of SS-40 and AS-40 in 30-40 cm soil layer was significantly lower than SS-30, AS-30 and CK, and the compactness of SS-40 was significantly lower than AS-40 

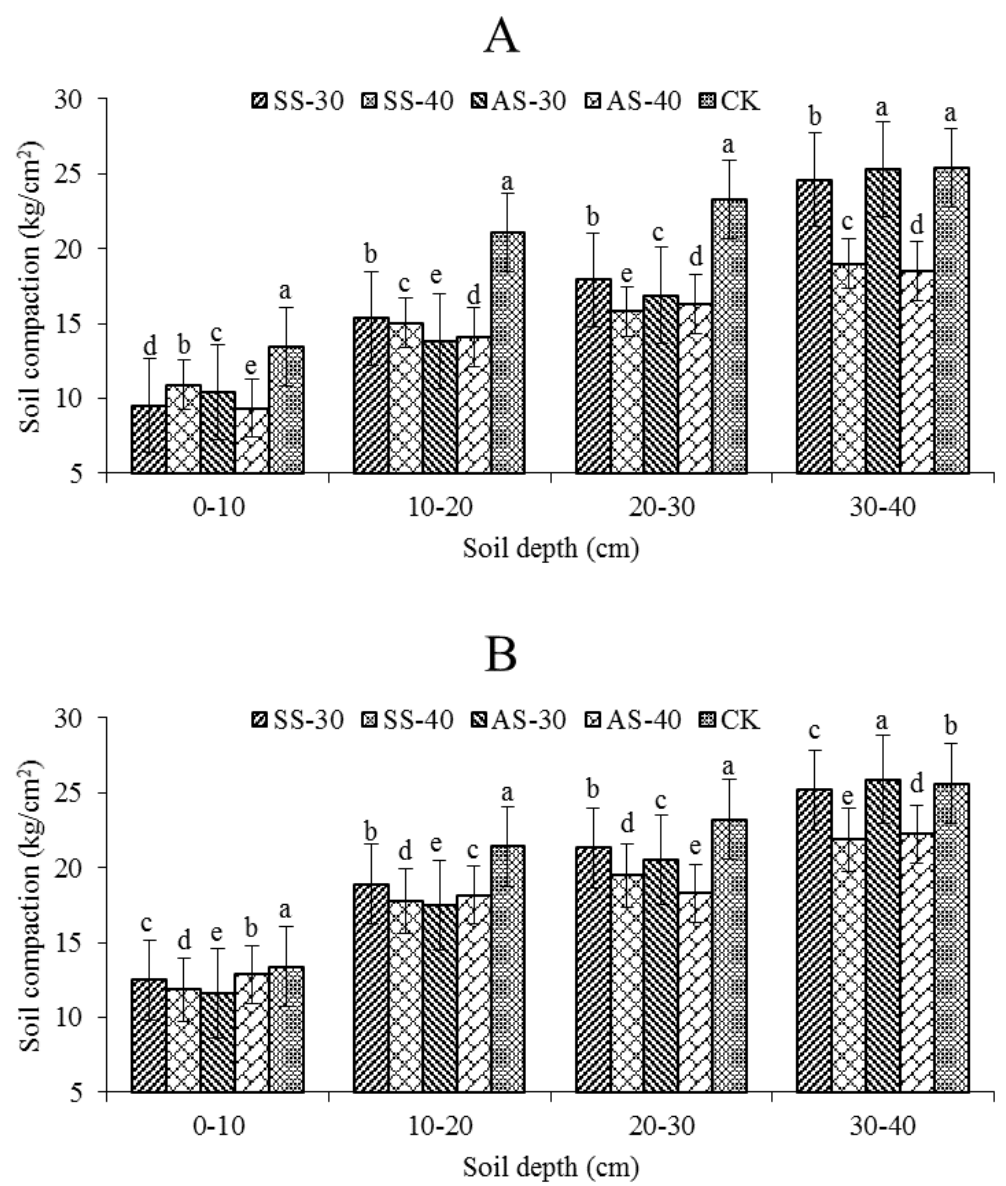

Fig. 2: Comparison of soil compactness in 2015 (A) and 2016 (B). In the figure, different lowercase letters indicate significant differences in the level of $P<0.05$. The same below

(Fig. 2B).

In 2015, the bulk density of subsoiling treatment in 0 $30 \mathrm{~cm}$ soil layer is significantly lower than CK. In $0-20 \mathrm{~cm}$ soil layer the bulk density of AS-30 and AS-40 was significantly lower than of SS-40 and SS-30, and the bulk density of AS-30 was significantly lower than of AS-40, the bulk density of SS-40 was significantly lower than of SS-30 (Fig. 3A). In 20-30 cm soil layer the bulk density of SS-40 and AS-40 was significantly lower than of AS-30 and SS-30 (Fig. 3A). The bulk density of AS-40 and SS-40 in 30-40 $\mathrm{cm}$ soil layer was significantly lower than AS-30, SS-30 and $\mathrm{CK}$, and the bulk density of AS-40 was significantly lower than SS-40 (Fig. 3A).

In 2016, the bulk density of subsoiling treatment in 0 $30 \mathrm{~cm}$ soil layer was significantly lower than of CK. In 0-10 $\mathrm{cm}$ soil layer the bulk density of AS-40 and SS-40 was significantly lower than in SS-30 and AS-30. In 10-30 cm soil layer the bulk density of SS-30 and AS-30 was significantly lower than of AS-40 and SS-40, and SS-30 was significantly lower than of AS-30 (Fig. 3B). In $30-40 \mathrm{~cm}$ soil layer the bulk density of AS-40 and SS-40 was significantly lower than of AS-30 and SS-30, and the bulk density of AS-40 was significantly lower than of SS-40 (Fig.
3B).

The soil moisture content of each treatment was relatively high at sowing time. The soil moisture content of AS-30 and AS-40 in 20-40 cm soil layer was significantly higher than of SS-30, SS-40 and CK. In 40-60 cm and 60$80 \mathrm{~cm}$ soil layers the soil moisture content was significantly higher than of CK (Fig. 4A). At seedling stage, soil moisture content of AS-30, AS-40 and SS-40 in 0-20 cm soil layer was significantly higher than of SS-30 and CK (Fig. 4B), the soil moisture content of $20-40 \mathrm{~cm}$ soil layer subsoiling treatment was significantly higher than of CK. The soil moisture content of SS-40 and AS-40 in 40-60 cm soil layer was significantly higher than of SS-30, AS-30 and CK. At jointing stage, the soil moisture content of subsoiling treatment in $0-80 \mathrm{~cm}$ soil layer was significantly higher than $\mathrm{CK}$ and there was a maximum difference between the soil moisture content of subsoiling treatment in $20-40 \mathrm{~cm}$ soil layer and of CK (Fig. 4C). At silking stage, the soil moisture content of subsoiling treatment in $0-100 \mathrm{~cm}$ soil layer was significantly higher than of CK, in $20-40 \mathrm{~cm}$ soil layer the soil moisture content of AS-40 and AS-30 was significantly higher than of SS-40 and SS-30, the soil moisture content of AS-40 was significantly higher than of AS-30 (Fig. 4D). 

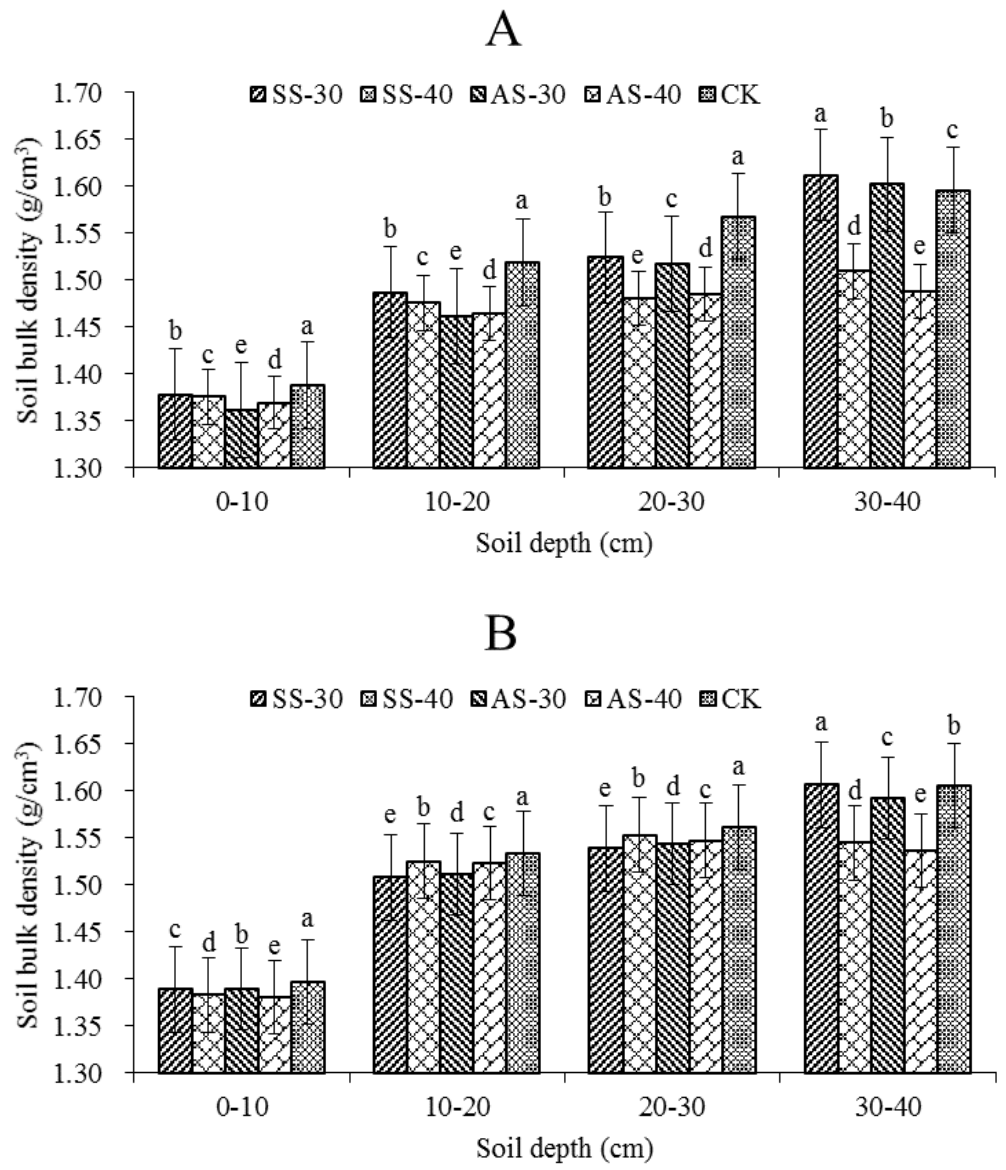

Fig. 3: Comparison of soil bulk density in 2015 (A) and 2016 (B)

During the filling stage, the soil moisture content of subsoiling treatment in $0-40 \mathrm{~cm}$ soil layer was significantly higher than of CK, the soil moisture content of AS-40 and SS-40 in 40-80 cm soil layer was significantly higher than of AS-30, SS-30 and CK (Fig. 4E). The soil moisture content of SS-40, SS-30 and AS-30 in 0-20 cm soil layer was significantly higher than CK at maturity stage, and that of subsoiling treatment in $20-80 \mathrm{~cm}$ soil layer was significantly higher than of CK (Fig. 4F).

\section{Effect of subsoiling on root activity}

Maize roots in the soil layer of $0-40 \mathrm{~cm}$ were dug at silking stage, and the activity indexes of the roots were measured by methylene blue colorimetric method and TTC reduction method. The total and active absorption area in maize roots of subsoiling treatment was significantly higher than those in CK (Fig. 5). The total absorption area of SS-40 and SS-30 roots was significantly higher than of AS-30 and AS-40 in 2015, and the active absorption area of SS-40 and SS-30 were significantly higher than of AS-30 and AS-40. The total and active absorption area of AS-40 were significantly higher than of SS-40, and that of AS-30 and SS-30 were significantly higher than of SS-30 in 2016. The total and active absorption area of AS-40 roots were significantly higher than of SS-40, while of AS-30 and SS-30 roots were significantly higher than of SS-30 in 2016.

The active absorption area / total absorption area ratio of SS-40 and SS-30 in 2015 was significantly higher than of AS-30, AS- 40 and CK, and the ratio of AS-40 and SS-40 in 2016 was significantly higher than of AS-30, SS-30 and CK (Table 2). The total specific surface area, active specific surface area, TTC reduction amount and root activity of subsoiling treatment were significantly higher than those of CK in 2015 and 2016. The active specific surface area of SS-40, SS-30, AS-40 and AS-30 were 3.44, 2.47, 0.26 and $0.03 \%$ were higher than CK in 2015, and the root activity was $21.9517 .74,8.99$ and $5.80 \%$ higher than of CK, respectively. The active specific surface area of AS-40, SS40 , AS-30 and SS-30 were 2.47, 1.85, 1.32 and $0.62 \%$ higher than those of CK in 2016, and the root activity were $20.37,18.23,7.83$ and $5.92 \%$ higher than CK, respectively.

\section{Effects of subsoiling on leaf photosynthetic characteristics}

The $C_{i}, T_{r}, G_{s}$ and $P_{n}$ of subsoiling treatments in 2015 were significantly higher than CK, in which SS-40 and SS-30 
Yan et al. / Intl J Agric Biol, Vol 25, No 4, 2021

Table 2: Comparison of root activity indices of maize

\begin{tabular}{lllllll}
\hline Year & Treatments & $\begin{array}{l}\text { Actively absorption surface/Total } \\
\text { absorption surface }(\%)\end{array}$ & $\begin{array}{l}\text { Total specific surface } \\
\left(\mathrm{cm}^{2} / \mathrm{mL}\right)\end{array}$ & $\begin{array}{l}\text { Active specific surface } \\
\left(\mathrm{cm}^{2} / \mathrm{mL}\right)\end{array}$ & $\begin{array}{l}\text { Reductive amount of TTC } \\
\text { by root }(\mu \mathrm{g})\end{array}$ & $\begin{array}{l}\text { Root vigor } \\
(\mu \mathrm{g} / \mathrm{g} / \mathrm{h})\end{array}$ \\
\hline 2015 & SS-30 & $32.74 \mathrm{~b}$ & $12.64 \mathrm{~b}$ & $11.63 \mathrm{~b}$ & $37.97 \mathrm{~b}$ & $75.94 \mathrm{~b}$ \\
& SS-40 & $33.18 \mathrm{a}$ & $12.70 \mathrm{a}$ & $11.74 \mathrm{a}$ & $39.33 \mathrm{a}$ & $78.66 \mathrm{a}$ \\
& AS-30 & $32.01 \mathrm{c}$ & $12.54 \mathrm{~d}$ & $11.35 \mathrm{~d}$ & $34.12 \mathrm{~d}$ & $78.24 \mathrm{~d}$ \\
& AS-40 & $31.96 \mathrm{~d}$ & $12.58 \mathrm{c}$ & $11.38 \mathrm{c}$ & $35.15 \mathrm{c}$ & $70.30 \mathrm{c}$ \\
& CK & $31.86 \mathrm{e}$ & $12.52 \mathrm{e}$ & $11.35 \mathrm{~d}$ & $32.25 \mathrm{e}$ & $6.50 \mathrm{e}$ \\
2016 & SS-30 & $31.85 \mathrm{~d}$ & $12.35 \mathrm{~d}$ & $11.42 \mathrm{~d}$ & $34.63 \mathrm{~d}$ & $77.30 \mathrm{~b}$ \\
& SS-40 & $32.89 \mathrm{a}$ & $12.48 \mathrm{~b}$ & $11.56 \mathrm{~b}$ & $38.65 \mathrm{~b}$ & $70.50 \mathrm{c}$ \\
& AS-30 & $32.28 \mathrm{c}$ & $12.42 \mathrm{c}$ & $11.50 \mathrm{c}$ & $35.25 \mathrm{c}$ & $78.70 \mathrm{a}$ \\
& AS-40 & $32.87 \mathrm{a}$ & $12.53 \mathrm{a}$ & $11.63 \mathrm{a}$ & $39.35 \mathrm{a}$ & $65.38 \mathrm{e}$ \\
\hline
\end{tabular}

Table 3: Comparison of photosynthetic indices and $W U E$ of maize leaves

\begin{tabular}{|c|c|c|c|c|c|c|}
\hline Year & Treatments & $\frac{C_{i}}{(\mu \mathrm{mol} / \mathrm{mol})}$ & $\begin{array}{l}T_{r} \\
\left(\mathrm{mmol} / \mathrm{m}^{2} \mathrm{~s}^{-1}\right)\end{array}$ & $\begin{array}{l}G_{s} \\
\left(\mathrm{~mol} / \mathrm{m}^{2} \mathrm{~s}^{-1}\right)\end{array}$ & $\begin{array}{l}P_{n} \\
\left(\mu \mathrm{mol} / \mathrm{m}^{2} \mathrm{~s}^{-1}\right)\end{array}$ & $\begin{array}{l}\text { WUE } \\
(\mu \mathrm{mol} / \mathrm{mmol})\end{array}$ \\
\hline \multirow[t]{4}{*}{2015} & SS-30 & $121.4 \mathrm{~b}$ & $5.91 \mathrm{~b}$ & $0.43 \mathrm{~b}$ & $45.6 \mathrm{~b}$ & $7.71 \mathrm{a}$ \\
\hline & SS-40 & $133.2 \mathrm{a}$ & $6.16 \mathrm{a}$ & $0.44 \mathrm{a}$ & $47.6 \mathrm{a}$ & $7.73 \mathrm{a}$ \\
\hline & AS-40 & $118.6 \mathrm{c}$ & $5.66 \mathrm{c}$ & $0.41 \mathrm{c}$ & $42.8 \mathrm{c}$ & $7.57 \mathrm{~b}$ \\
\hline & $\mathrm{CK}$ & $110.2 \mathrm{e}$ & $5.11 \mathrm{e}$ & $0.39 \mathrm{e}$ & $37.3 \mathrm{e}$ & $7.30 \mathrm{c}$ \\
\hline \multirow[t]{5}{*}{2016} & SS-30 & $109.1 \mathrm{~b}$ & $5.12 \mathrm{~d}$ & $0.39 \mathrm{c}$ & $38.0 \mathrm{c}$ & $7.43 \mathrm{c}$ \\
\hline & SS-40 & $114.3 \mathrm{~b}$ & $5.58 \mathrm{c}$ & $0.41 \mathrm{~b}$ & $42.7 \mathrm{~b}$ & $7.65 \mathrm{~b}$ \\
\hline & AS-30 & $118.2 \mathrm{ab}$ & $5.78 \mathrm{~b}$ & $0.43 \mathrm{a}$ & $44.7 \mathrm{a}$ & $7.73 \mathrm{a}$ \\
\hline & AS-40 & $126.4 \mathrm{a}$ & $6.02 \mathrm{a}$ & $0.44 \mathrm{a}$ & $46.6 \mathrm{a}$ & $7.75 \mathrm{a}$ \\
\hline & CK & $109.3 \mathrm{~b}$ & $5.07 \mathrm{e}$ & $0.39 \mathrm{c}$ & $37.6 \mathrm{c}$ & $7.41 \quad \mathrm{c}$ \\
\hline
\end{tabular}

Table 3: Comparison of photosynthetic indices and WUE of maize leaves

\begin{tabular}{|c|c|c|c|c|c|c|}
\hline \multirow[t]{2}{*}{ Year } & Treatments & $C_{i}$ & $T_{r}$ & $G_{s}$ & $P_{n}$ & WUE \\
\hline & & $(\mu \mathrm{mol} / \mathrm{mol})$ & $\left(\mathrm{mmol} / \mathrm{m}^{2} \mathrm{~s}^{-1}\right)$ & $\left(\mathrm{mol} / \mathrm{m}^{2} \mathrm{~s}^{-1}\right)$ & $\left(\mu \mathrm{mol} / \mathrm{m}^{2} \mathrm{~s}^{-1}\right)$ & $(\mu \mathrm{mol} / \mathrm{mmol})$ \\
\hline \multirow[t]{4}{*}{2015} & SS-30 & $121.4 \mathrm{~b}$ & $5.91 \mathrm{~b}$ & $0.43 \mathrm{~b}$ & $45.6 \mathrm{~b}$ & $7.71 \mathrm{a}$ \\
\hline & SS-40 & $133.2 \mathrm{a}$ & $6.16 \mathrm{a}$ & $0.44 \mathrm{a}$ & $47.6 \mathrm{a}$ & $7.73 \mathrm{a}$ \\
\hline & AS-40 & $118.6 \mathrm{c}$ & $5.66 \mathrm{c}$ & $0.41 \mathrm{c}$ & $42.8 \mathrm{c}$ & $7.57 \mathrm{~b}$ \\
\hline & $\mathrm{CK}$ & $110.2 \mathrm{e}$ & $5.11 \mathrm{e}$ & $0.39 \mathrm{e}$ & $37.3 \mathrm{e}$ & $7.30 \mathrm{c}$ \\
\hline \multirow[t]{5}{*}{2016} & SS-30 & $109.1 \mathrm{~b}$ & $5.12 \mathrm{~d}$ & $0.39 \mathrm{c}$ & $38.0 \mathrm{c}$ & $7.43 \mathrm{c}$ \\
\hline & SS-40 & $114.3 \mathrm{~b}$ & $5.58 \mathrm{c}$ & $0.41 \mathrm{~b}$ & $42.7 \mathrm{~b}$ & $7.65 \mathrm{~b}$ \\
\hline & AS -30 & $118.2 \mathrm{ab}$ & $5.78 \mathrm{~b}$ & $0.43 \mathrm{a}$ & $44.7 \mathrm{a}$ & $7.73 \mathrm{a}$ \\
\hline & AS -40 & $126.4 \mathrm{a}$ & $6.02 \mathrm{a}$ & $0.44 \mathrm{a}$ & $46.6 \mathrm{a}$ & $7.75 \mathrm{a}$ \\
\hline & $\mathrm{CK}$ & $109.3 \mathrm{~b}$ & $5.07 \mathrm{e}$ & $0.39 \mathrm{c}$ & $37.6 \mathrm{c}$ & $7.42 \mathrm{c}$ \\
\hline
\end{tabular}

Table 4: Comparison of root-cap ratio and WUE of each treatment

\begin{tabular}{llllll}
\hline Year & Treatments & Total dry weight $(\mathrm{g})$ & Root dry weight $(\mathrm{g})$ & Root-shoot ratio $(\%)$ & WUE per plant $(\mathrm{g} / \mathrm{mm})$ \\
\hline 2015 & SS-30 & $237.3 \mathrm{~b}$ & $21.32 \mathrm{~b}$ & $8.98 \mathrm{~d}$ & $0.49 \mathrm{~b}$ \\
& SS-40 & $254.1 \mathrm{a}$ & $21.57 \mathrm{a}$ & $8.49 \mathrm{e}$ & $0.52 \mathrm{a}$ \\
& AS-30 & $208.6 \mathrm{~d}$ & $20.91 \mathrm{~d}$ & $10.02 \mathrm{~b}$ & $0.43 \mathrm{~d}$ \\
& AS-40 & $224.5 \mathrm{c}$ & $21.24 \mathrm{c}$ & $9.46 \mathrm{c}$ & $0.46 \mathrm{c}$ \\
& CK & $193.5 \mathrm{e}$ & $20.73 \mathrm{e}$ & $10.71 \mathrm{a}$ & $0.40 \mathrm{e}$ \\
& SS-30 & $198.8 \mathrm{c}$ & $20.63 \mathrm{~b}$ & $10.38 \mathrm{~b}$ & $0.47 \mathrm{c}$ \\
& SS-40 & $225.1 \mathrm{~b}$ & $20.81 \mathrm{ab}$ & $9.25 \mathrm{c}$ & $0.54 \mathrm{~b}$ \\
& AS-30 & $226.4 \mathrm{~b}$ & $20.91 \mathrm{ab}$ & $9.24 \mathrm{c}$ & $0.54 \mathrm{~b}$ \\
& AS-40 & $248.8 \mathrm{a}$ & $20.96 \mathrm{a}$ & $8.43 \mathrm{~d}$ & $0.59 \mathrm{a}$ \\
& CK & $188.6 \mathrm{~d}$ & $20.29 \mathrm{c}$ & $10.76 \mathrm{a}$ & $0.45 \mathrm{~d}$ \\
\hline
\end{tabular}

were significantly higher than AS-40 and AS-30, and SS-40 was significantly higher than of SS-30 (Table 3). The WUE of SS-40, SS-30 and AS-40 was significantly higher than of AS-30 and CK, among which, the WUE of SS-40 and SS30 was significantly higher than AS-40 and AS-30, and of SS-40 was significantly higher than of SS-30. The WUE of
SS-40, SS-30, AS-40 and AS-30 leaves were 5.62, 5.89, 0.68 and $3.70 \%$ higher than CK, respectively. In 2016 the $C_{i}, T_{r}, G_{s}$ and $P_{n}$ of subsoiling treatment were higher than CK, in which the $T_{r}, G_{s}$ and $P_{n}$ of AS-40, AS-30 and SS-40 were significantly higher than those of SS-30 and CK, and the $C_{i}, T_{r}, G_{s}$ and $P_{n}$ of AS-40 were significantly higher than 
A

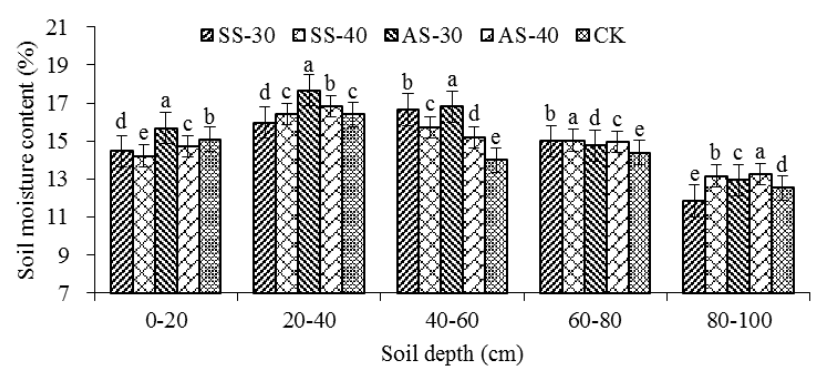

$\mathrm{B}$

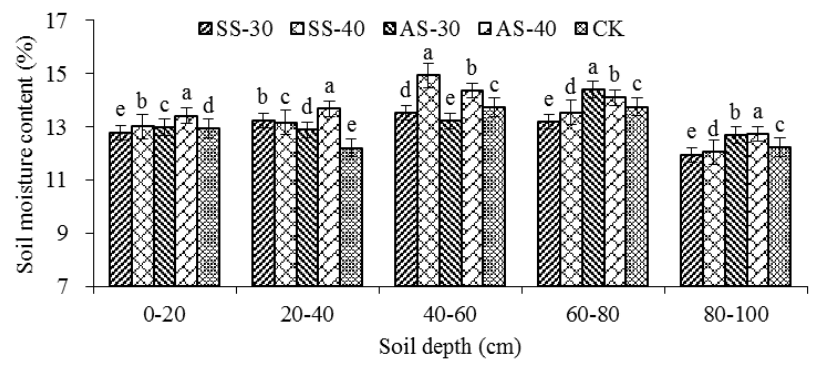

$\mathrm{C}$

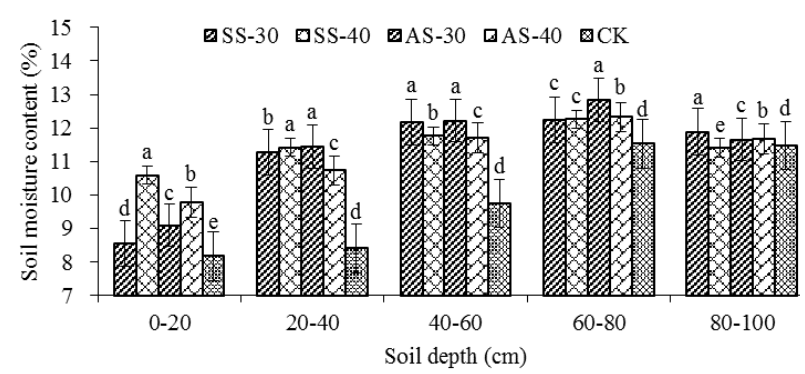

$\mathrm{D}$

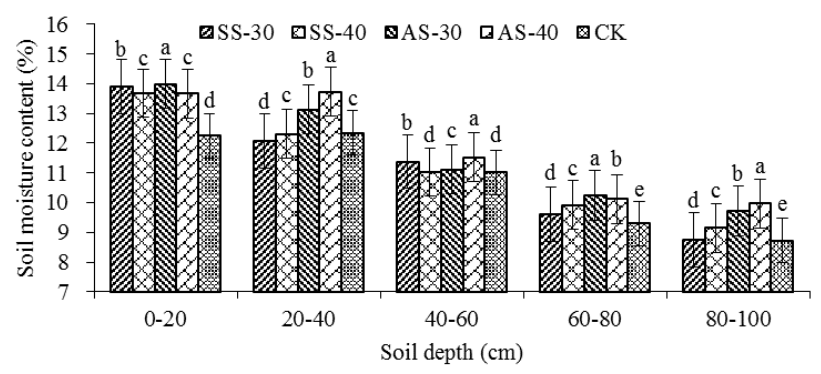

$\mathrm{E}$

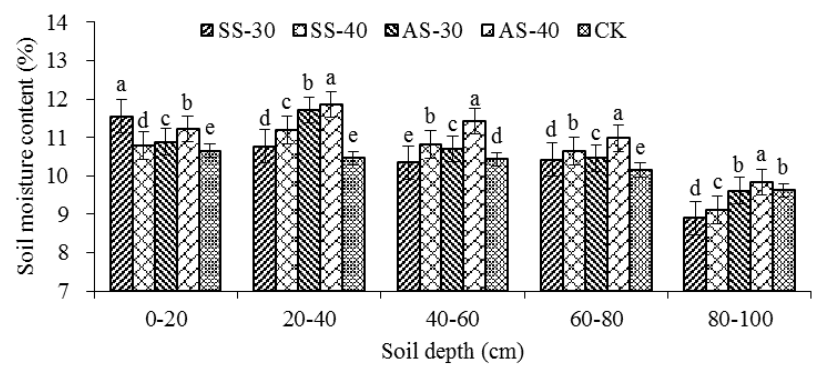

$\mathrm{F}$

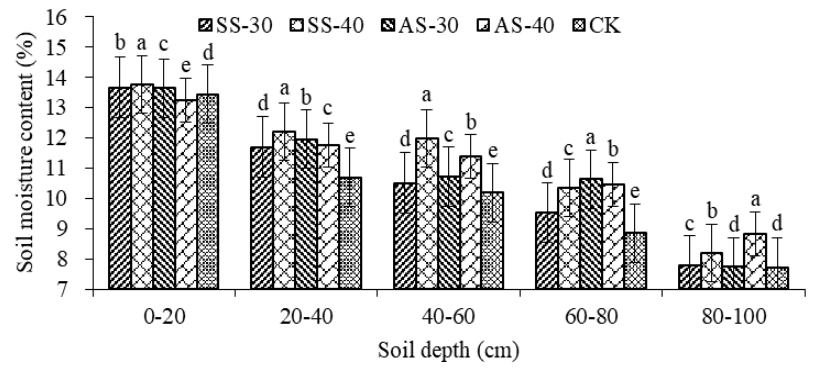

Fig. 4: Comparison of soil moisture content in 2016. In the figure, A is the Sowing stage, B is the Seedling stage, C is the Jointing stage, $\mathrm{D}$ is the Silking stage, $\mathrm{E}$ is the Filling stage, $\mathrm{F}$ is the Maturity stage

SS-40. The WUE of subsoiling treatment was higher than of CK, in which AS-40, AS-30 and SS-40 was significantly higher than CK, and AS-40 and AS-30 was significantly higher than SS-40 and SS-30. The WUE of SS-40, SS-30, AS-40 and AS-30 was 0.27, 3.29, 4.32 and $4.59 \%$ higher than CK, respectively.

\section{Effects of subsoiling on root-cap ratio and WUE per plant}

Subsoiling could affect dry matter accumulation, root shoot ratio and WUE per plant. The total aboveground dry weight, $0-40 \mathrm{~cm}$ root dry weight and WUE per plant of subsoiling treatment were significantly higher than $\mathrm{CK}$, and the rootshoot ratio of subsoiling treatment was significantly lower than CK (Table 4). The total dry weight, root dry weight and WUE per plant of SS-40 and SS-30 were significantly higher than AS-40 and AS-30 in 2015, in which SS-40 were significantly higher than SS-30. The root-shoot ratio of SS40 and SS-30 was significantly lower than AS-40 and AS-
30 , and the root-shoot ratio of SS-40 were significantly higher than SS-30. WUE per plant of SS-40, SS-30, AS-40 and AS-30 was 22.5, 30.0, 7.5 and 15.0\% higher than CK, respectively. The aboveground total dry weight, $0-40 \mathrm{~cm}$ root dry weight and WUE of per plant of AS-40 were significantly higher than AS-30, SS-40 and SS-30 in 2016, among which, the aboveground total dry weight and WUE of per plant of AS-30 were significantly higher than those of SS-30. The root-shoot ratio of AS-40 was significantly lower than AS-30, SS-40 and SS-30, among which the rootshoot ratios of AS-30 and SS-40 were significantly lower than of SS-30. Per plant WUE of SS-40, SS-30, AS-40 and AS-30 was $4.4,20.0,20.0$ and $31.1 \%$ higher than CK, respectively.

\section{Effects of subsoiling on Yield and WUE}

Subsoiling could affect maize yield and WUE. There was no significant difference in grain number per spike between 
Yan et al. / Intl J Agric Biol, Vol 25, No 4, 2021

Table 5: Comparison of yield components, yield and population WUE of maize

\begin{tabular}{clllll}
\hline Year & Treatments & Kernels per ear & 100-kernel Weight $(\mathrm{g})$ & Yield $\left(\mathrm{kg} / \mathrm{hm}^{2}\right)$ & Population WUE $(\mathrm{kg} / \mathrm{mm})$ \\
\hline 2015 & SS-30 & $652 \mathrm{a}$ & $34.7 \mathrm{a}$ & $12197.1 \mathrm{~b}$ & $25.20 \mathrm{~b}$ \\
& SS-40 & $651 \mathrm{a}$ & $35.8 \mathrm{a}$ & $12748.8 \mathrm{a}$ & $26.34 \mathrm{a}$ \\
& AS-30 & $646 \mathrm{a}$ & $33.2 \mathrm{~b}$ & $11662.0 \mathrm{c}$ & $24.10 \mathrm{c}$ \\
& AS-40 & $646 \mathrm{a}$ & $33.6 \mathrm{~b}$ & $11708.5 \mathrm{c}$ & $24.19 \mathrm{c}$ \\
& CK & $638 \mathrm{a}$ & $32.9 \mathrm{~b}$ & $11585.2 \mathrm{c}$ & $23.94 \mathrm{c}$ \\
& SS-30 & $598 \mathrm{~cd}$ & $30.2 \mathrm{~d}$ & $10528.3 \mathrm{c}$ & $25.3 \mathrm{c}$ \\
& SS-40 & $604 \mathrm{bc}$ & $32.0 \mathrm{c}$ & $10921.0 \mathrm{~b}$ & $26.3 \mathrm{~b}$ \\
& AS-30 & $612 \mathrm{~b}$ & $34.1 \mathrm{~b}$ & $11066.8 \mathrm{~b}$ & $26.6 \mathrm{~b}$ \\
& AS-40 & $628 \mathrm{a}$ & $36.6 \mathrm{a}$ & $11639.1 \mathrm{a}$ & $28.0 \mathrm{a}$ \\
& CK & $590 \mathrm{~d}$ & $29.6 \mathrm{~d}$ & $10332.1 \mathrm{c}$ & $24.8 \mathrm{c}$ \\
\hline
\end{tabular}
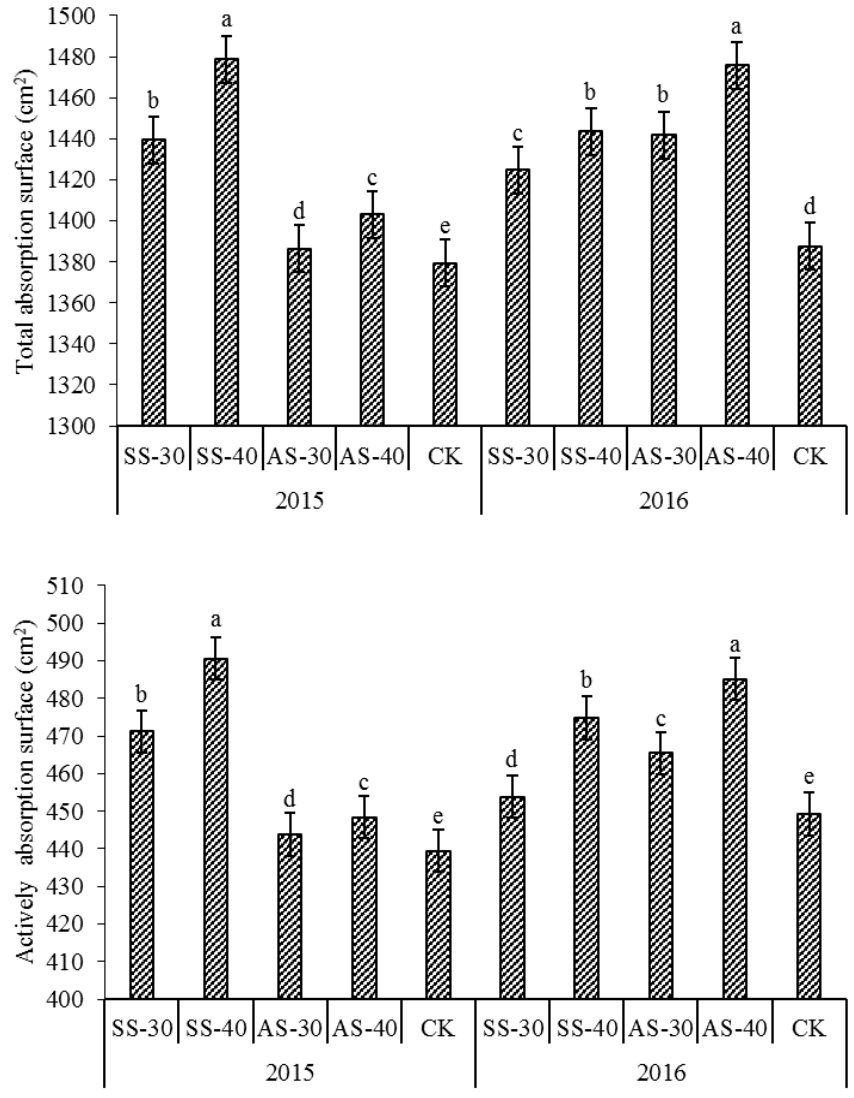

Fig. 5: Comparison of total absorption area and active absorption area of maize root

subsoiling and CK in 2015 (Table 5). The WUE of 100 grain weight, yield and population of subsoiling were higher than CK, in which SS-40 and SS-30 were significantly higher than of AS-40, AS-30 and CK, and the yield and population WUE of SS-40 were significantly higher than SS-30. The WUE of SS-40, SS-30, AS-40 and AS-30 was $5.26,10.03,0.67$ and $1.04 \%$ higher than CK, respectively. The 100-grain weight, yield and population WUE of AS-40, AS-30 and SS-40 were significantly higher than of SS-30 and CK in 2016, in which AS-40 was significantly higher than of AS-30 and SS-40, and AS-30 was significantly higher than of SS-30. The WUE of SS-40, SS-30, AS-40 and AS-30 was 2.02, 6.05, 7.26 and $12.9 \%$ higher than CK, respectively.

\section{Discussion}

The present study found that subsoiling significantly reduced the soil penetration resistance and bulk density, and significantly increased the soil water content from subsoiling part to the surface, which was consistent with previous research conclusions. It also found that compactness and bulk density of subsoiling in 2015 were lower than in 2016.

Xu et al. (2012) found that subsoiling can significantly reduce the soil compactness of plough bottom and increase the soil moisture of plough layer. Liu et al. (2015) studied that subsoiling can significantly reduce soil volume, increase soil water infiltration and increase field water holding 
capacity. It is further confirmed that subsoiling can effectively last for at least one growing season (Hamilton $e t$ al. 2019). In the range of subsoiling, the soil water content of subsoiling in $20-40 \mathrm{~cm}$ soil layer is significantly higher than $\mathrm{CK}$, which is basically consistent with the research results of Xiao et al. (2011). To conclude effect of subsoiling on soil penetration resistance, bulk density and water content will gradually decreases with time. Because the upper soil is greatly influenced by environmental and mechanical operation, the effect of subsoiling on the upper soil is weakened rapidly. Properly increasing the subsoiling depth can effectively improve the soil regulation of subsoiling. In arid areas, subsoiling can improve soil water storage and soil moisture conservation, delay water loss and enhance soil drought resistance.

Qin et al. (2008) and Zhang et al. (2015) concluded that subsoiling can promote root depth distribution, retard root senescence and improve root activity in soil. Holloway and Holloway (1991), Zhang et al. (2004) and Lv et al. (2019) concluded that subsoiling was beneficial to root fixation and ligation, and could promote root absorption of water and nutrients in soil. Based on previous studies, found that subsoiling can significantly improve the total absorption area, active absorption area, total specific surface area, active specific surface area and TTC reduction amount of maize root system, and deeply analyzed the effect of subsoiling on the activity and growth of maize root system. Based on the comparison of root activity indexes in two years, it is considered that the promotion effect of subsoiling on root activity will gradually weaken with the extension of interval time. Appropriate increase of subsoiling depth can enhance root activity.

Feng et al. (2015) considered that subsoiling could improve the photosynthetic leaf area of maize and significantly increase the $P_{n}$ of leaves in different layers. Jin et al. (2014) and Xie et al. (2019) considered that subsoiling was beneficial to improve SPDA value, LAI, net photosynthetic rate and leaf area duration of maize leaves. Further experiments confirm that subsoiling can not only increase $P_{n}$ but also increase $C_{i}, T_{r}, G_{s}$ and leaf WUE. It is found that the influence of subsoiling on $C_{i}, T_{r}, G_{s}, P_{n}$ and leaf WUE will gradually weaken with time, and the appropriate increase of subsoiling depth can delay the effect of subsoiling.

Izumi et al. (2009) considered that subsoiling has significant positive effects on biomass and yield. Zheng et al. (2013) found that subsoiling can improve the dry matter accumulation in wheat and promote the distribution of photosynthates to grain. Cai et al. (2014) and Guan et al. (2014) concluded that subsoiling can regulate root growth and exudates, promote soil nutrient uptake, increase biomass and grain yield. In this study, the results showed that subsoiling significantly increased dry weight of aboveground parts and roots, significantly decreased root shoot ratio, significantly increased WUE of individual plants, and further clarified the effect of subsoiling on plant growth and dry matter accumulation. Through analysis, it was also find that the promotion effect of subsoiling on growth and material accumulation will weaken with time and increase the depth of subsoiling will prolong the maintenance time of subsoiling.

The results showed that subsoiling significantly increased 100 grain weight and yield, and significantly increased the population WUE of maize. Ishaq et al. (2003) studied that soil nutrient utilization rate was high after subsoiling, and soil nutrient utilization rate was positively correlated with nutrient uptake and grain yield. concluded that subsoiling can improve nitrogen use efficiency and grain yield. Zheng et al. (2015) believed that subsoiling can increase the yield of maize and wheat in Northeast, Northwest and North China, and the yield of plots with continuous subsoiling and no tillage increased significantly. Through the analysis of population WUE, yield and component factors in this experiment, the promotion effect of subsoiling on maize yield and population WUE was clarified, which further confirmed the previous research conclusions. Based on the analysis of the experimental results, it is considered that increasing the subsoiling depth is an effective method to improve its effect, which can significantly improve the crop yield and population WUE.

\section{Conclusion}

In conclusion, subsoiling can effectively improve the soil structure, enhance the water holding capacity of the soil in arid areas, delay water loss, improve root activity, net photosynthetic rate, dry matter accumulation and WUE, and promote crop growth and yield. Subsoiling in autumn has the best effect on soil improvement. Increasing the subsoiling depth properly can improve its effect, but will gradually weaken with the passage of time.

\section{Acknowledgment}

Thanks to the Project of Natural Science Foundation of Jilin Province (No. 202512JC010272903) and China National Corn Industry Technology System Project (No. : CARS-0242) for supporting this research. I would like to thank corresponding author Professor $\mathrm{Gu}$ Yan and Researcher Bian Shaofeng for their guidance and help in writing this article.

\section{Author Contributions}

WY and SB conceived the idea; LZ, HZ and GT contributed in planning the experiments; CX, NS and FL participated in the implementation of the experiment; WY, YG and CX analyzed data; YG, SB and WY finalized the paper.

\section{Conflict of Interest}

There is no conflict of interest among the authors and institutions where the research has been conducted 


\section{Data Availability Declaration}

Primary and supplementary data reported in this article are available with the corresponding authors

\section{References}

Bao SD (2000). Soil Agrochemical Analysis, $3^{\text {rd }}$ edn. China Agriculture Press, Beijing, China

Baumhardt RL, OR Jones, RC Schwartz (2008). Long-term effects of profile-modifying deep plowing on soil properties and crop yield. Soil Sci Soc Amer J 72:677-682

Cai HG, W Ma, XZ Zhang, JQ Ping, XG Yan, JZ Liu, JC Yuan, LC Wang, J Ren (2014). Effect of subsoil tillage depth on nutrient accumulation, root distribution, and grain yield in spring maize. Crop J 5:297-307

Feng Y, CL Wang, YX Zhang, JH Zhang, EEDG Bao, LH Gao, D Wang, D Wang, W Zheng, C Zhang (2015). Effects of deep scarification on yield and photosynthetic characteristics of maize in Dry Irrigated Area. J Jilin Agric Sci 1:23-28

Ghosh PK, M Mohanty, KK Bandyopadhyay, DK Painuli, AK Misra (2005). Growth, competition, yields advantage and economics in soybean/pigeonpea intercropping system in semi-arid tropics of India. Field Crops Res 1:90-97

Guan DH, MM Al-Kaisi, YS Zhang, LS Duan, WM Tan, MC Zhang, ZH Li (2014). Tillage practices affect biomass and grain yield through regulating root growth, root-bleeding sap and nutrients uptake in summer maize. Field Crops Res 157:89-97

Hamilton GJ, D Bakker, G Akbar, I Hassan, Z Hussain, A McHugh, S Raine (2019). Deep blade loosening increases root growth, organic carbon, aeration, drainage, lateral infiltration and productivity. Geoderma 345:72-92

Han XZ, WX Zou, FX Wang, FJ Wang (2009). Construction effect of fertile cultivated layer in black soil. Chin J Appl Ecol 12:2996-3002

He J, HW Li, HT Chen, CY Lu, QJ Wang (2018). Research progress of conservation tillage technology and machine. Trans Chin Soc Agric Machinery 4:1-19

He J, HW Li, XY Wang, AD McHugh, WY Li, HW Gao, NJ Kuhn (2006). The adoption of annual subsoiling as conservation tillage in dryland maize and wheat cultivation in northern China. Soil Till Res 94:493502

Holloway RE, AR Dexter (1991). Tillage and compaction effects on soil properties, root growth and yield of wheat during drought in a semiarid environment. Soil Technol 3:233-253

Ingrid GM, C Prat, C Ovalle, A Pozo, N Stolpe, E Zagal (2012). Subsoiling improves conservationtillagein cereal production of severely degraded Alfisols under Mediterranean climate. Geoderma 189-190:10-17

Ishaq DM, M Ibrahim, R Lal (2003). Tillage and fertilizer effects on root growth of wheat and cotton on a sandy clay loam in Pakistan. $J$ Sustain Agric 3:43-57

Izumi Y, T Yoshida, M Iijima (2009). Effects of subsoiling to the non-tilled field of wheat-soybean rotation on the root system development, water uptake, and yield. Plant Prod Sci 3:327-335

Jin PY, W Ren, HB Tao, P Wang (2014). Effects of subsoiling on dry matter production, photosynthetic performance and root development of summer maize. J Maize Sci 1:114-120

Kaur R, VK Arora (2019). Deep tillage and residue mulch effects on productivity and water and nitrogen economy of spring maize in north-west India. Agric Water Manage 213:724-731

Li LJ, YH Cui, Q Li, QL Xue, M Zhao (2011). Effect on yield performance of early spring maize in strip deep tillage. Crops 5:96-99

Liu WL, SX Cheng, N Li, J Wu, L Yang, CH Li, YL Zhao (2020). Effects of time and pattern of deep tillage on topsoil nutrient content, yield of winter wheat and summer maize in lime concretion black soil. Henan Agric Sci 3:8-16

Liu ZD, ZG Liu, DF Ning, AZ Tai, JQ Nan, X Zhang, JF Xiao (2015). Effects of subsoiling tillage on water utilization and yield of maize. $J$ Irrig Drain 5:6-12
Lv GH, W Han, HB Wang, WB Bai, JQ Song (2019). Effect of subsoiling on tillers, root density and nitrogen use efficiency of winter wheat in loessal soil. Plant Soil Environ 9:456-462

Ping CZ, M Hong, WD Wang, BYNML Zhao, L Mei, PF Liu, WYG Zhao (2020). Effect of tillage management modes on farmland physical properties in black soil region. Chin Agric Sci Bull 7:83-89

Qi H, M Liu, WJ Zhang, ZP Zhang, XF Li, ZW Song, JL Yu, YN Wu (2012). Effect of deep loosening mode on soil physical characteristics and maize root distribution. Acta Agric Boreali-Sin 4:191-196

Qin HL, WS Gao, YC Ma, L Ma, CM Yin (2008). Effects of subsoiling on soil moisture under no-tillage 2 years later. Sci Agric Sin 1:78-85

Schneider F, A Don, I Hennings, O Schmittmann, SJ Seidel (2017). The effect of deep tillage on crop yield - What do we really know? Soil Till Res 174:193-204

Wang JD, DJ Cui, S Li, ZH Liu, SL Zhuang, SH Song, XW Liu (2019). Effect of subsoiling time on physical and chemical properties of lime concretion black soil under wheat-corn continuous cropping mode. Shandong Agric Sci 10:86-90

Wang SB, LL Guo, PC Zhou, XJ Wang, Y Shen, HF Han, TY Ning, K Han (2019). Effect of subsoiling depth on soil physical properties and summer maize (Zea mays L.) yield. Plant, Soil Environ 65:131-137

Wang XY, HW Gao, HW Li, XX Zhou (2000). Experimental study on runoff and erosion under conservative tillage. Trans CSAE 3:66-69

Wei GJ, SC Jian, HM Fang, QJ Peng, MM Niu (2019). Current situation and prospect of conservation tillage technology in dry-farming areas of North China. J Chin Agric Mech 3:195-200, 211

Xiao JB, ZX Sun, JT Yang, YL Zhang, JM Zheng, L Liu (2011). Effect of subsoiling on soil water and crop yield in semi-arid area. Chin J Soil Sci 3:709-714

Xie GH, XF Yu, JL Gao, SP Hu, HZ Bao, FG Wang, J Liu (2019). Effects of the deep pine and controlled-release fertilizer on the photosynthetic characteristics and yield of maize. J Northern Agric 5:54-59

Xie JH, LL Wang, LL Li, JA Coulter, Q Chai, RZ Zhang, ZZ Luo, P Carberry, KPC Rao (2020). Subsoiling increases grain yield, water use efficiency, and economic return of maize under a fully mulched ridge-furrow system in a semiarid environment in China. Soil Till Res 199:104584

Xu L, ZC Wang, CW Zhao, MW Zhu, BW Wei (2012). Effect of sub-soiling on soil physical characteristics of low-yield dryland in the West of Jilin Province. Soil Crop 2:121-125

Zhai Z, YY Li, HC Pang, J Wang, L Zhang, GH Dong, JJ Guo, ZH Guo (2016). Study on present situation and characteristics of plow pan in the northern region of Huang Huai Hai Plain. Sci Agric Sin 12:23222332

Zhang Q, H Wang, SL Wang, YH Zhang, R Wang, XL Wang, J Li (2020). Effects of tillage alternation pattern with subsoiling on soil physical and chemical properties and spring maize yield in the Loess Plateau, China. Chin J Appl Ecol 2:459-466

Zhang RF, HS Yang, JL Gao, YQ Zhang, ZG Wang, XY Fan, WB Bi (2015). Effect of subsoiling on root morphological and physiological characteristics of spring maize. Transactions CSAE 5:78-84

Zhang XY, D Pei, SY Chen (2004). Root growth and soil water utilization of winter wheat in the North China Plain. Hydrol Proc 12:2275-2287

Zhao YL, ZW Xue, HB Guo, XY Mu, CH Li (2014). Effects of tillage and straw returning on water consumption characteristics and water use efficiency in the winter wheat and summer maize rotation system. Sci Agric Sin 17:3359-3371

Zheng CY, ZW Yu, YL Zhang, D Wang, Y Shi, ZZ Xu (2013). Effects of subsoiling and supplemental irrigation on dry matter production and water use efficiency in wheat. Acta Ecol Sin 7:2260-2271

Zheng K, J He, HW Li, QJ Wang, WY Li (2015). Meta-analysis on maize and wheat yield under subsoiling in Northern China. Trans CSAE $22: 7-15$

Zhu XC, FB Song, SQ Liu, TD Liu (2011). Effects of arbuscular mycorrhizal fungus on photosynthesis and water status of maize under high temperature stress. Plant Soil 346:189-199

Zou Q (1997). Instruction of Plant Physiological and Biochemical Experiments. China Agriculture Press, Beijing, China 